\title{
An Innovative Approach to Improving the Proposed CMS Star Rating "Statin Use in Persons with Diabetes"
}

\author{
Thomas Vanderholm, PharmD; Hannah M. Renner, PharmD, MPH; \\ Samuel F. Stolpe, PharmD, MPH; and Alex J. Adams, PharmD, MPH
}

\begin{abstract}
SUMMARY
The Statin Use in Persons with Diabetes (SUPD) measure has been adopted by the Centers for Medicare and Medicaid Services as a display measure for Medicare Part C and Part D plan sponsors and is slated for inclusion within the primary star rating measure set. As such, the measure has become a focal point for quality improvement efforts by many health plans. Current pharmacy-based interventions reported in the literature involve pharmacists recommending that a patient's provider issue a prescription for a statin; studies to date have not shown that this intervention has been effective for the majority of patients with diabetes.

One innovative option is pharmacist prescriptive authority of statins for patients with diabetes. In such a model, a pharmacist identifies a patient with diabetes who is not on a statin, assesses the patient for contraindications and appropriateness of therapy, and works directly with the patient to close the gap in care. This solution could lead to earlier initiation of statin therapy and reduce the burdens associated with multiple communications with the patient's primary care provider. In 2018, Idaho became the first state to allow pharmacist prescribing to close the SUPD measure, with certain regulatory safeguards in place.
\end{abstract}

J Manag Care Spec Pharm. 2018;24(11):1126-29

Copyright $\odot 2018$, Academy of Managed Care Pharmacy. All rights reserved.

I n November 2014, the membership of the Pharmacy Quality Alliance (PQA) endorsed a new quality metric for health plans designed to improve cardiovascular outcomes for persons with diabetes. ${ }^{1}$ The Statin Use in Persons with Diabetes (SUPD) measure looks at the percentage of patients aged 40-75 years who have been dispensed a medication for diabetes and who have also received a statin medication, with some patient exclusions. ${ }^{2}$ The SUPD has since been adopted by the Centers for Medicare and Medicaid Services (CMS) as a display measure for Medicare Part C and Part D plan sponsors and is slated for inclusion within the primary star rating measure set. As such, the measure has become a focal point for quality improvement efforts by many health plans.

Health plans have since deployed a variety of resources to improve performance on the SUPD measure, including leveraging their pharmacy networks. Despite the increased attention related to the SUPD metric, pharmacists have experienced some challenges associated with improving performance on the measure. This class of medications, however, is uniquely positioned for a more innovative approach to quality improvement efforts through pharmacist prescriptive authority of statins for persons with diabetes. This is due to an increasing precedent of pharmacist prescriptive authority in the United States for certain medication classes, the overall strong safety profile of statins, and pharmacists' established record of successful pharmacotherapeutic management specific to statins.

\section{Genesis of the SUPD Measure}

Atherosclerotic cardiovascular disease (ASCVD) is the leading cause of morbidity and mortality for individuals with diabetes. $^{3}$ Patients with diabetes have a 3-fold increased absolute adjusted risk of cardiovascular disease death and a $60 \%$ lifetime chance of dying from heart disease. ${ }^{4,5}$ A meta-analysis of over 18,000 patients with diabetes concluded that for each $\mathrm{mmol} / \mathrm{L}$ reduction in low-density lipoprotein (LDL) cholesterol pursuant to starting statin therapy, there was a 9\% reduction in all-cause mortality and a $13 \%$ reduction in vascular mortality. ${ }^{6}$ Because of this, the American College of Cardiology (ACC) and the American Heart Association (AHA) recommended statin therapy as the primary prevention of ASCVD in individuals with diabetes who are aged 40-75 years. ${ }^{3}$ The ACC/AHA recommendation for statin therapy is independent of the patient's baseline LDL level.

Despite the understanding of the important role that statins play in primary prevention, an analysis of 204 cardiology practices between May 2008 and October 2013 from the ACC's PINNACLE registry reported that $38 \%$ of patients with diabetes between the ages of 40-75 years are not on statin therapy, representing a gap in care. ${ }^{7}$ Wide practice-level variation was observed in the use of statins in patients with diabetes, suggesting this as an opportunity for quality improvement. In a separate study of 130 primary care and outpatient Veterans Affairs facilities between October 2012 and October 2013, a comparable $39 \%$ of patients with diabetes (who did not have cardiovascular disease) were not on statin therapy. ${ }^{8}$

The CMS has adopted the PQA measure of SUPD, using it on its display page and announcing plans to add it to the Part D star ratings in 2019. Health plans have variable performance on the SUPD measure, with 2017 CMS display ratings (informed by 2015 data) from 528 Medicare Part D contracts ranging from $59 \%$ to $89 \%$ with a mean (standard deviation) of $75 \%$ (4.1\%) from plans reporting data. ${ }^{9}$

\section{Current Pharmacy-Based Interventions}

With the inclusion of the SUPD measure in the CMS star ratings program for Medicare Part C and Part D, health plans 
have increasingly turned to pharmacy-based interventions to close the gap in care and improve outcomes for patients with diabetes. Pharmacists have used various technology platforms to identify and target patients with diabetes who are not on a statin and may benefit from primary prevention.

Several studies have been conducted to assess the effectiveness of a pharmacist intervention involving contacting the prescriber with a statin recommendation. Renner et al. (2017) deployed an intervention in which a pharmacist would first call a prescriber with a recommendation, then, if a statin was not prescribed in 5-10 days, send a fax to the prescriber. ${ }^{10}$ If a statin was still not prescribed in another 5-10 days, the pharmacist would send a second fax. The intervention group received a prescription for a statin at a higher rate than patients in the control group $(20.8 \%$ vs. $8.5 \%$, respectively, $P<0.001)$. Nonetheless, $80 \%$ of attempts were unsuccessful in obtaining a statin prescription in the intervention group, and for every 13 prescribers contacted, only 1 statin prescription was obtained and dispensed to a patient. ${ }^{9}$

Similar studies have shown low prescriber acceptance rates of statin recommendations from pharmacists, ranging from $16.6 \%$ to $32.4 \% .^{10-13}$ In many cases, the prescriber did not respond at all. McClain et al. (2017) received no response from the prescriber on $62 \%$ of the pharmacist's recommendations. ${ }^{13}$ In the instances when a prescriber responded, reasons for not prescribing a statin often reflected a misunderstanding of the ACC/AHA clinical guidelines. Studies have found that a common reason for prescribers declining to add a statin was that the patient's lipids were controlled, despite the ACC/AHA recommendation being independent of the patient's LDL level., ${ }^{912}$

\section{An Innovative Approach to Closing the SUPD Gap: Pharmacist Prescriptive Authority}

Studies on pharmacy-based interventions that depend on recommendations that a patient's provider issue a prescription for a statin have not proven effective for the majority of patients with diabetes. Even when limited success was demonstrated, it came at the expense of efficiency for the pharmacy and some delay to therapy for the patient. ${ }^{10}$ Innovative approaches are therefore worthy of consideration.

One option is pharmacist prescriptive authority for statins for patients with diabetes. In such a model, a pharmacist identifies a patient with diabetes who is not on a statin, assesses the patient for contraindications and appropriateness of therapy, and works directly with the patient to close the gap in care. This solution could lead to earlier initiation of statin therapy and reduce the burdens associated with multiple communications with the patient's primary care provider.

There are several reasons that this approach may be the most appropriate and expedient. First, there is an established precedent for the exercise of prescriptive discretion by U.S. pharmacists for some medication classes. States have increasingly granted pharmacists prescriptive authority for drugs, including immunizations, tobacco cessation products, epinephrine auto-injectors, hormonal contraceptives, and opioid antagonists, among others..$^{14-16}$

Second, the statin class of medications overall has a strong safety profile. Over the past 2 decades, the U.S. Food and Drug Administration has considered a transition from prescription to over-the-counter status for statins on multiple occasions. ${ }^{17-19}$ Historical concerns have focused on the inability of patients to self-treat because of the need for liver function testing before statin initiation and a fear that "patients may not understand who should not use the products," among other reasons. ${ }^{19}$ While these concerns have not generally played out in jurisdictions that have already made the transition for statins from prescription-only to over-the-counter status-for example, the United Kingdom - they can be mitigated by having a medication expert such as a pharmacist assess and manage patients.

Finally, pharmacists have a successful track record of initiating and monitoring statins under collaborative practice authority, and recent studies have also demonstrated success with independent pharmacist prescriptive authority in Canada. One such study evaluated the efficacy of pharmacist prescribing of statins in dyslipidemia. ${ }^{20}$ The 2016 study found that pharmacist prescribing versus standard care in 99 patients led to a $25 \%$ absolute increase in the number of patients achieving LDL targets. ${ }^{21}$ A subsequent 2017 study was carried out with 723 patients and was designed for pharmacists to prescribe or adjust statins and medications for hypertension and diabetes based on risk analysis, lab results, and medication management review. ${ }^{21}$ No adverse events were reported in the trial, and the pharmacist intervention achieved a $21 \%$ greater relative reduction in estimated risk for patient cardiovascular events compared with the control group.

With pharmacists demonstrating success with independent prescriptive authority in Canada for many drug classes, including statins, it seems reasonable and appropriate to allow U.S. pharmacists limited prescriptive authority of statins for patients with previously diagnosed diabetes. The ACC/AHA guidelines give their strongest evidence-based recommendation for primary prevention with statin therapy even without a diagnosis of hypercholesterolemia, so it is not necessary for pharmacists to diagnose; they are merely adding a preventive medication in accordance with clinical guidelines.

On July 1, 2018, Idaho became the first state to allow pharmacists to prescribe statins for patients previously diagnosed with diabetes. ${ }^{22}$ The Idaho regulations require pharmacists to use a patient assessment protocol based on current clinical guidelines that specify patient inclusion and exclusion criteria and explicit medical referral criteria. Thus, pharmacists are only able to prescribe for patients with diabetes who are aged 40-75 years and who do not have contraindications and do not meet other exclusion or cautionary criteria specified in 
the guidelines (e.g., heart failure or on hemodialysis). This approach ensures that there is a true gap in care and that a statin is not initiated in a patient who should not be on a statin. Pharmacists are expected to collect all relevant information in accordance with state guidelines, including appropriate liver function tests. The Idaho regulations further require the development of a patient-specific follow-up care plan and monitoring in accordance with clinical guidelines. In addition, pharmacists must notify the patient's provider of record of any statin initiated within 5 business days to reduce fragmentation and ensure continuity of care. ${ }^{22}$

\section{Conclusions}

Implementation of the ACC/AHA recommendation to prescribe statins as primary prevention for diabetes patients aged 40-75 years has been suboptimal. The serious gap in uptake is leaving almost $40 \%$ of these patients at increased risk for ASCVD and its related complications. ${ }^{6}$ To better close this gap in care, states may want to consider an approach similar to that of Idaho in which pharmacists can prescribe statins for patients with diabetes within an appropriate regulatory framework.

\section{Authors}

THOMAS VANDERHOLM, PharmD, Washington State University, Spokane; HANNAH M. RENNER, PharmD, MPH, Pharmacy and Therapeutics, University of Pittsburgh School of Pharmacy, Pittsburgh, Pennsylvania; SAMUEL F. STOLPE, PharmD, MPH, Scientific Technology Corporation, San Francisco, California; and ALEX J. ADAMS, PharmD, MPH, Idaho State Board of Pharmacy, Boise.

AUTHOR CORRESPONDENCE: Alex J. Adams, PharmD, MPH, Executive Director, Idaho State Board of Pharmacy,

1199 W. Shoreline Ln., Ste. 303, Boise, ID 83702.

Tel.: 419.708.5186; E-mail: AlexAdamsRPh@gmail.com.

\section{DISCLOSURES}

No funding supported the writing of this article. The authors have nothing to disclose.

\section{REFERENCES}

1. Pharmacy Quality Alliance. PQA endorses new performance measure and receives NQF endorsement on two additional measures. PQA Quality Connection. November/December 2014. Available at: http://pqaalliance.org/ images/uploads/files/3_PQA\%20Endorses\%20New\%20Performance\%20 Measure\%20and\%20Receives\%20NQF\%20Endorsement.pdf. Accessed August 10, 2018
2. Centers for Medicare \& Medicaid Services. Announcement of calendar year (CY) 2018 Medicare Advantage capitation rates and Medicare Advantage and Part D payment policies and final call letter and request for information. April 3, 2017. Available from: https://www.cms.gov/Medicare/Health-Plans/ MedicareAdvtgSpecRateStats/Downloads/Announcement2018.pdf. Accessed August 10, 2018.

3. Stone NJ, Robinson JG, Lichtenstein AH, et al. 2013 ACC/AHA guideline on the treatment of blood cholesterol to reduce atherosclerotic cardiovascular risk in adults: a report of the American College of Cardiology/ American Heart Association Task Force on Practice Guidelines. Circulation. 2014;129(25 Suppl 2):S1-45.

4. Eldor R, Raz I. American Diabetes Association indicators for statins in diabetes: is there evidence? Diabetes Care. 2009;32(2):S384-91.

5. Almekinder E. The connection between diabetes, heart disease, and stroke. The Diabetes Council. Available at: https://www.thediabetescouncil com/the-connection-between-diabetes-heart-disease-and-stroke/. Accessed August 10, 2018.

6. Cholesterol Treatment Trialists' (CTT) Collaborators, Kearney PM, Blackwell L, et al. Efficacy of cholesterol-lowering therapy in 18,686 people with diabetes in 14 randomised trials of statins: a meta-analysis. Lancet. 2008;371(9607):117-25.

7. Pokharel Y, Gosch K, Nambi V, et al. Practice-level variation in statin use among patients with diabetes: insights from the PINNACLE Registry. J Am Coll Cardiol. 2016;68(12):1368-69.

8. Pokharel Y, Akeroyd JM, Ramsey DJ, et al. Statin use and its facilitylevel variation in patients with diabetes: insight from the Veterans Affairs National Database. Clin Cardiol. 2016;39(4):185-91.

9. Hines L. Pharmacy Quality Alliance comments to the Idaho State Board of Pharmacy. In: Minutes of the Idaho State Board of Pharmacy. Page 4. August 30, 2017. Available at: https://bop.idaho.gov/board_meeting/2017-10-31_Approved_Minutes_Aug-30.pdf. Accessed August 10, 2018.

10. Renner HM, Hollar A, Stolpe SF, Marciniak MW. Pharmacist-toprescriber intervention to close therapeutic gaps for statin use in patients with diabetes: a randomized controlled trial. J Am Pharm Assoc (2003). 2017;57(3S):S236-42.el.

11. Doellner JF, Dettloff RW, DeVuyst-Miller S, Wenstrom KL. Prescriber acceptance rate of pharmacists' recommendations. J Am Pharm Assoc (2003). 2017;57(3S):S197-202

12. Szobonya J, Ostyn J, Cleveland K, Spann N. Potential impact of pharmacist direct recommendation for statin medication in high-risk patients: strategy for closing the care gap. Poster presented at: Idaho Society for HealthSystem Pharmacists Meeting, October 2017, Sun Valley, ID.

13. McClain R, Nola K, Poulio J, Blackburn H, Bennett A. Effectiveness of pharmacist intervention on initiating statin therapy in diabetes patients. Res Soc Adm Pharm. 2017;13(4):e19.

14. Adams AJ, Weaver KK. The continuum of pharmacist prescriptive authority. Ann Pharmacother. 2016;50(9)778-84.

15. Adams AJ. Pharmacist prescriptive authority for epinephrine auto-injectors in Idaho. Inov Pharm. 2016;7(3):Article 14. Available at: https://pubs.lib.umn. edu/index.php/innovations/article/view/457/451. Accessed August 10, 2018.

16. Adams AJ, Suchanek Hudmon K. Pharmacist prescriptive authority for smoking cessation medications in the United States. J Am Pharm Assoc (2003). 2018;58(3):253-57.

17. Yasgur BS. Should statins be available over-the-counter? An expert interview with Robert Eckel, MD. MPR. June 13, 2016. Available at: https://www. empr.com/features/should-statins-be-available-over-the-counter-an-expertinterview-with-robert-eckel-md/article/502468/. Accessed August 10, 2018

18. LaMattina J. Pfizer pulls the plug on OTC lipitor and it's the patient's fault. Forbes. July 29, 2015. Available at: https://www.forbes.com/sites/ johnlamattina/2015/07/29/pfizer-pulls-the-plug-on-otc-lipitor-and-its-thepatients-fault/. Accessed August 10, 2018. 
19. Pray WS, Pray GE. New statin risks and the battle for OTC status. U.S. Pharm. 2015;40(2):12-15. Available at: https://www.uspharmacist.com/ article/new-statin-risks-and-the-battle-for-otc-status. Accessed August 10, 2018.

20. Tsuyuki R, Rosenthal M, Pearson G. A randomized trial of a communitybased approach to dyslipidemia management: pharmacist prescribing to achieve cholesterol targets (RxACT Study). Can Pharm J. 2016;149(5):283-92.
21. Al Hamarneh YN, Hemmelgarn BR, Hassan I, Jones CA, Tsuyuki RT. The effectiveness of pharmacist interventions on cardiovascular risk in adult patients with type 2 diabetes: the multicentre randomized controlled RxEACH Trial. Can J Diabetes. 2017;41(6):580-86.

22. Idaho State Board of Pharmacy. Rule Docket 27-0104-1701. Rules governing pharmacist prescriptive authority. Available at: https://adminrules. idaho.gov/rules/current/27/270104.pdf. Accessed September 8, 2018. 